\title{
TEMPERATURE DEPENDENT SOLUBILITY STUDIES OF BRIGATINIB IN SOME PURE SOLVENTS USEFUL IN DOSAGE FORM DEVELOPMENT
}

\author{
SAAD M. ALSHAHRANI ${ }^{1}$, MUQTADER MOHAMMAD*1, MD. KHALID ANWER*1, \\ FARHAT FATIMA ${ }^{1}$, ABDULLAH S. ALSHETAILI' ${ }^{1}$, AHMED ALALAIWE ${ }^{1}$, \\ BADER B. ALSULAYS ${ }^{1}$ and FAIYAZ SHAKEEL ${ }^{2}$ \\ ${ }^{1}$ Department of Pharmaceutics, College of Pharmacy, \\ Prince Sattam Bin Abdulaziz University, Al-Kharj, Kingdom of Saudi Arabia \\ ${ }^{2}$ Departmentof Pharmaceutics, College of Pharmacy, King Saud University, Riyadh, \\ Kingdom of Saudi Arabia
}

\begin{abstract}
In the current study, thermodynamic dissolution of brigatinib in six pure solvents namely, water, ethanol, isopropyl myristate (IPM), poly(ethylene glycol)-400 (PEG-400), dichloromethane (DCM) and ethyl acetate (EA) at (298.2-323.2 K) temperature and 0.1 MPa atm. pressure were carried out using flask shaking technique. The mole-fraction solubility of brigatinib was obtained greatest in IPM $\left(6.09 \times 10^{-2}\right)$ and least in water $\left(3.12 \times 10^{-6}\right)$ at $298.2 \mathrm{~K}$. Experimentally obtained solubilities values of brigatinib were regressed using adapted Apelblat equation with root mean square deviations in the range of 1.91 to 4.67 in all solvents and similar trends were observed with increased the temperature. The solubility data generated in this investigation could be helpful for investigator for analysis/dosage form development of brigatinib.
\end{abstract}

Keyword: thermodynamic dissolution, mole fraction solubility, lung cancer, curve fitting, Apelblat model

The development of brigatinib (BGB) is the annexation of a phosphorous-containing dimethyl phosphine oxide (DMPO) group. This DMPO group on the aniline at $\mathrm{C} 4$ in the structure has the selective affinity with anaplastic lymphoma kinase (ALK) inhibitor that exhibits superior inhibitory effects against harboring Non-small cell lung cancers (NSCLCs) (1, 2). Lung cancer is the predominant cause of mortality, tobacco comprising 6000 components damaged the DNA and accountable for $90 \%$ of lung cancer (3). Brigatinib chemotherapeutic agent used in the treatment of different types of solid tumours especially for NSLC showed 12- folds greater potency $\left(\mathrm{IC}_{50} ; 10 \mathrm{nmol} / \mathrm{L}\right)$ against all $17 \mathrm{sec}-$ ondary ALK mutants tested across a panel of $\mathrm{ALK}^{+}$ cell lines. BGB maintained a high degree of inhibitory activity over more than 250 kinases compared with crizotinib and ceritinib, alectinib first and second-generation anaplastic lymphoma kinase (ALK) tyrosine kinase inhibitors $(4,5)$. In recent past, BGB was approved by US-FDA as an anticancer moiety, under fast approval based on tumor response and duration followed by its promotion as ALUNBRIG ${ }^{\mathrm{TM}}$ tablets in two strengths of $30 \mathrm{mg}$ and $90 \mathrm{mg}$. BGB has the molecular formula $\mathrm{C}_{29} \mathrm{H}_{39} \mathrm{ClN}_{7} \mathrm{O}_{2} \mathrm{P}$ and Mol.wt; $584.102 \mathrm{~g} / \mathrm{mol}$ (Fig. 1). The Chemical Abstracts Service (CAS) number is 1197953-54-0 with its Medical Subject Heading MeSHAP26113. Its physicochemical properties include off-white<smiles>COc1cc(N2CCC(N3CCN(C)CC3)CC2)ccc1Nc1ncc(Cl)c(Nc2ccccc2P(C)(C)=O)n1</smiles>

Figure 1. Brigatinib molecular structure (molar mass: $584.10 \mathrm{~g}$ $\left.\mathrm{mol}^{-1}\right)$

\footnotetext{
* Corresponding author: e-mail: (MM) mo.ahmed@psau.edu.sa, (MA) mkanwer2002@yahoo.co.in
} 
solid with $\mathrm{pKa}$ in the range of $1.73 \pm 0.02$ to $8.04 \pm$ 0.01 (base) soluble in organic solvents viz; ethanol and dimethylformamide DMF but sparingly soluble in aqueous solution and insoluble in water $(6,7)$. Among the different methods utilized to increase the solubility, co-solvency was found to be the simple and reproducible and industrial acquainted process. In due process of formulation and development, innumerable solvents could be used from the process of raw material untill the finished formulations (8). In view of the suggestions of International Council for Harmonization of Technical Requirements for Pharmaceuticals for Human Use (ICH) and according to the direction of industry Q3C specialists just class 2 and class 3 solvents ought to be chosen for solubility test. Nevertheless, the temperature dependent solubility of BGB and its correlation with mathematical models in any solvents not yet available in any of the scientific literature. The adapted Apelblat and Van't Hoff mathematical models are usually utilized to compare the experimental with theoretical solubility data (9-11).

Therefore the purpose of the current study was to determine the solubility and solutions thermodynamics of BGB by applying Apelblat and van't Hoff models in solvents namely, water, ethanol, isopropyl myristate (IPM), dichloromethane (DCM) and ethyl acetate (EA) at $298.2 \mathrm{~K}$ to $323.2 \mathrm{~K}$ temperature and $0.1 \mathrm{MPa}$ atmospheric pressure. The investigated temperature range $(298.2 \mathrm{~K}$ to $323.2 \mathrm{~K}$ ) was selected randomly in such a way that the maximum investigated temperature $(323.2 \mathrm{~K})$ should not exceed the melting temperature $(487.2 \mathrm{~K})$ of BGB.

\section{MATERIALS AND METHODS}

\section{Materials}

Brigatinib, ethanol, dichloromethane (IUPAC name: methylene dichloride), ethyl acetate, IPM (IUPAC name: isopropyl myristate) and PEG-400 [IUPAC name: poly (oxyethylene)] were purchased from Sigma-Aldrich (Saint Louis, MO). Double water was gotten from Milli-Q unit accessible in pharmaceutics research facility. The general properties of these materials near their properties are listed in Table 1.

\section{Evaluation of brigatinib solubility}

The flask-shake technology was used to evaluate mole-fraction solubility of BGB in six pharmaceutically accepted solvents free from impurities namely water, ethyl-alcohol, IPM, PEG-400, EA and DCM useful in dosage form development the temperature was ranged from (298.2 to 323.2$) \mathrm{K}$ under air pressure of 0.1 megaPascal. Adequately enough amount of BGB was added to $05 \mathrm{~mL}$ of each of the solvent enclosed in screw-capped glass flask all the setup was in triplicate. The dispersed drug in respective solvents was stirred by isothermal biological shaker (Daihan Lab Tech, Korea) at $100 \mathrm{rpm}$ for three days to reach the equilibrium. Samples under study kept on table to settle the BGB (solute) particles at the bottom of flask by gravitational force for about 2 h (12). All samples were centrifug at 6000 rpm for predetermined time (30 $\mathrm{min})$ then filtered through $0.45 \mu \mathrm{m}$ micro-filter paper to avoid hindrance, supernatant of the all samples were analyzed by UV spectroscopy (JASCO-Japan) at $\lambda$-max of $284 \mathrm{~nm}$ by diluting with an appropriate solvent (7). The calibration curve of BGB was plotted between the standard concentrations of BGB and measured spectrophotometric absorbance. The calibration curve of BGB was obtained a mass/mass basis which was observed as linear in concentration range of ( 0.5 to 15.0$) \mu \mathrm{g} / \mathrm{g}$ with coefficient of determination $\left(R^{2}\right)$ of 0.9998 . The regressed equation was obtained as $y=0.0492 x+0.0093$; in which $y$ is the measured spectrophotometric absorbance of BGB and $x$ is the concentration of BGB $(\mu \mathrm{g} / \mathrm{g})$. The concentration of BGB in solubility samples was determined using calibration curve $(\mu \mathrm{g} / \mathrm{g})$.

The ambiguity in experimental solubility and experimental temperature were observed as $1.70 \%$ and $0.16 \mathrm{~K}$ respectively. The data generated in the laboratory was used to calculate experimental molefraction solubility $\left(\boldsymbol{x}_{\mathrm{e}}\right)$ of BGB in all solvents with the help of equation-1 (13-15).

$$
\boldsymbol{x}_{\mathrm{e}}=\frac{m_{1} / M_{1}}{m_{1} / M_{1}+m_{2} / M_{2}}
$$

$m_{1}=$ mass of BGB $(\mathrm{g})$ and $m_{2}=$ masses of solvents (g); $M_{1}=$ mol. masses of BGB $(\mathrm{g} / \mathrm{mol})$ and $M_{2}=$ mol. masses of respective solvent $(\mathrm{g} / \mathrm{mol})$

\section{Powder X-ray Diffractometric (PXRD) analysis}

The characterization of solid phase of BGB in both pure and equilibrated sample was carried out using "Powder X-ray Diffractometric (PXRD)" technique for the evaluation of possible transformation of BGB after equilibrium. The PXRD spectra of $\mathrm{BGB}$ in pure and equilibrated samples were obtained using "Ultima IV Diffractometer (Rigaku Inc. Tokyo, Japan)" in the $2 \theta$ range of 2-120 at a scan speed of $0.5 / \mathrm{min}$. The tube anode utilized was " $\mathrm{Cu}$ with $\mathrm{Ka}=0.1540562 \mathrm{~nm}$ monochromatized with a graphite crystal (Rigaku Inc., Tokyo, Japan)". The spectra of BGB in pure and equilibrated samples were recorded at tube voltage and tube current of $40 \mathrm{kV}$ and $40 \mathrm{~mA}$, respectively in 


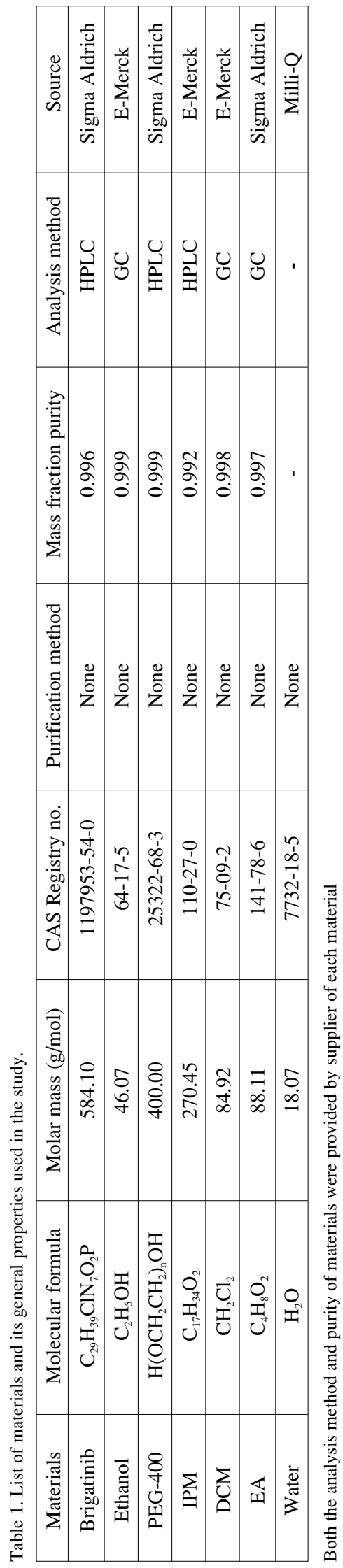

step scan mode (step size 0.02 , counting time $1 \mathrm{sec} / \mathrm{step})$.

\section{RESULTS AND DISCUSSION}

\section{Experimental solubility data of brigatinib}

Critical review of literature survey revealed that no single publication about temperature dependent solubility/dissolution of BGB in any solvent exist. However, the solubility values of in some pure solvent such as ethanol (43 $\mathrm{mg} / \mathrm{mL})$ and DMSO (1 $\mathrm{mg} / \mathrm{mL}$ ) at ambient temperature has been described in the available literature $(1,16)$. The obtained molefraction solubilit, in many pure solvents from temperature 298.2 to $323.2 \mathrm{~K}$ at atmospheric pressure, is documented in Table 2. Logarithmic solubility data of BGB at five different temperatures is presented in Figure 2. The experimental values of solubility were increased with respect to temperature in every one of the six solvents (Fig. 2). The solubility of BGB in mole fraction was observed highest in IPM $(6.09 \times$ $\left.10^{-2}\right)$ followed by DCM $\left(2.84 \times 10^{-2}\right)$, PEG-400 $(1.30$ $\left.\times 10^{-2}\right)$, ethanol $\left(4.71 \times 10^{-3}\right)$, EA $\left(3.31 \times 10^{-3}\right)$ and water $\left(3.12 \times 10^{-6}\right)$ at $298.2 \mathrm{~K}$ (Table 2$)$. The molefraction solubilities of BGB were found incomparably higher in IPM and DCM than in different solvents like PEG, ethanol, EA, and water. The obtained data shows that IPM and DCM are more powerful solvents for solubility/dissolution of BGB and it could be utilized for analytical method/formulation development.

\section{PXRD analysis}

The PXRD analysis was carried out for the evaluation of possible transformation of BGB from crystalline to amorphous/solvates after equilibrium. The PXRD spectra of BGB in pure and equilibrated samples are shown in Figure 3. The PXRD spectra of pure BGB presented sharp crystalline characteristics peaks at various $2 \theta$ values, showing crystalline nature of BGB (Fig. 3). The PXRD spectra of equilibrated BGB also presented sharp crystalline characteristics peaks at different $2 \theta$ values (Fig. 3). The PXRD spectra of BGB in pure and equilibrated samples were almost similar, indicating no transformation of BGB from crystalline to amorphous/polymorphic/solvates form after equilibrium.

\section{Apelblat correlation/curve fitting of BGB solu- bility}

A simple and wide range modified apelblat model was used to correspond/correlate the solubilities values of BGB. The mole-fraction solubility of BGB can be determined utilizing Apelblat model equation-2 $(17,18)$. 


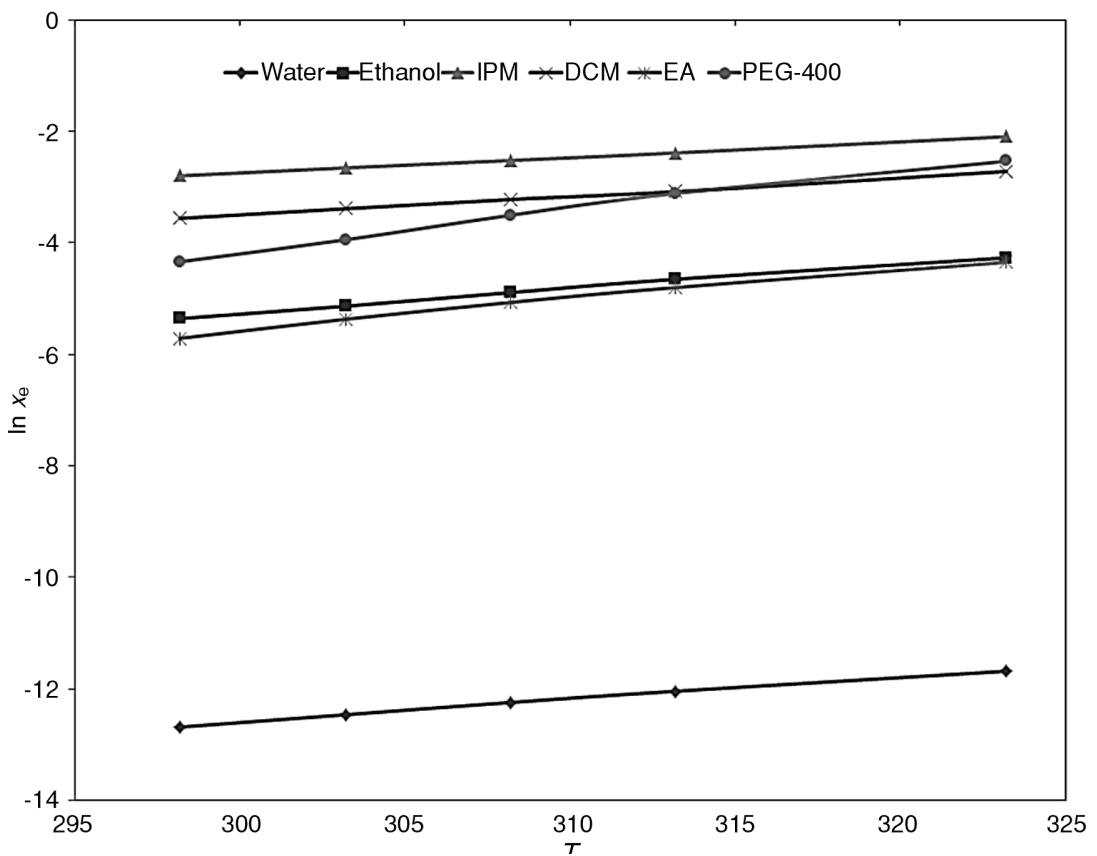

Figure 2. Experimental logarithmic solubilities of brigatinib in various pure solvents, water, ethanol, IPM (Isopropyl myristate), DCM (Dichloromethane), EA (Ethyl acetate), PEG-400 (polyethylene glycol 400) at five different temperatures
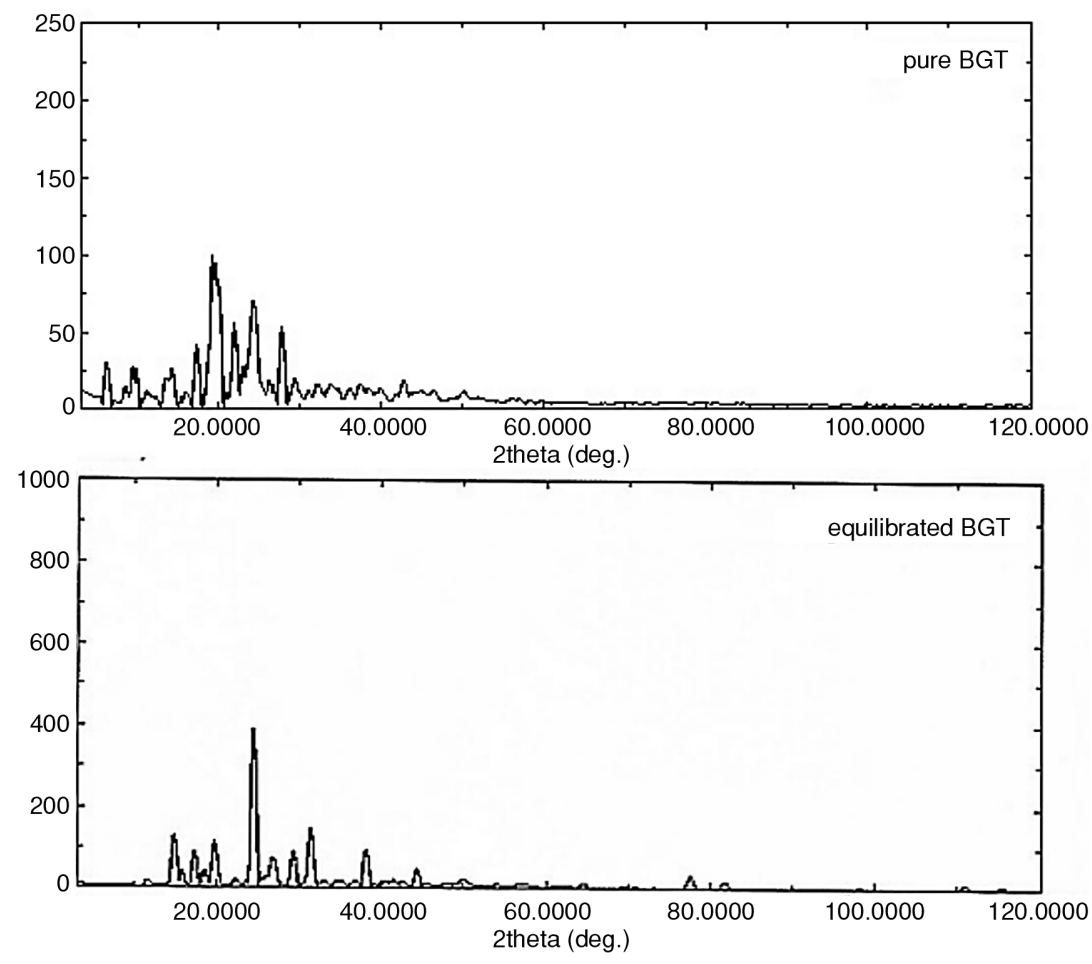

Figure 3. PXRD spectra of pure and equilibrated BGB showing no transformation of BGB 
Table 2. Experimental solubility $\left(x_{\mathrm{e}}\right)$ data of brigatinib in mole fraction in various pure solvents $(S)$ at " $T=298.2 \mathrm{~K}$ to $323.2 \mathrm{~K} " \&$ " $p=0.1$ $\mathrm{MPa}$ ".

\begin{tabular}{|c|c|c|c|c|c|}
\hline \multirow{2}{*}{$S$} & \multicolumn{5}{|c|}{$x_{\mathrm{e}}$} \\
\cline { 2 - 6 } & $T=298.2 \mathrm{~K}$ & $T=303.2 \mathrm{~K}$ & $T=308.2 \mathrm{~K}$ & $T=313.2 \mathrm{~K}$ & $T=323.2 \mathrm{~K}$ \\
\hline Water & $3.12 \times 10^{-6}$ & $3.89 \times 10^{-6}$ & $4.84 \times 10^{-6}$ & $5.92 \times 10^{-6}$ & $8.48 \times 10^{-6}$ \\
\hline Ethanol & $4.71 \times 10^{-3}$ & $5.88 \times 10^{-3}$ & $7.51 \times 10^{-3}$ & $9.53 \times 10^{-3}$ & $1.40 \times 10^{-2}$ \\
\hline IPM & $6.09 \times 10^{-2}$ & $7.02 \times 10^{-2}$ & $8.01 \times 10^{-2}$ & $9.17 \times 10^{-2}$ & $1.23 \times 10^{-1}$ \\
\hline PEG-400 & $1.30 \times 10^{-2}$ & $1.93 \times 10^{-2}$ & $3.00 \times 10^{-2}$ & $4.43 \times 10^{-2}$ & $7.90 \times 10^{-2}$ \\
\hline EA & $3.31 \times 10^{-3}$ & $4.65 \times 10^{-3}$ & $6.30 \times 10^{-3}$ & $8.23 \times 10^{-3}$ & $1.30 \times 10^{-2}$ \\
\hline DCM & $2.84 \times 10^{-2}$ & $3.37 \times 10^{-2}$ & $3.98 \times 10^{-2}$ & $4.58 \times 10^{-2}$ & $6.59 \times 10^{-2}$ \\
\hline
\end{tabular}

aThe standard uncertainties $u$ are $u(T)=0.16 \mathrm{~K}, u(p)=0.00 \mathrm{MPa}$ and $u_{\mathrm{r}}\left(x_{\mathrm{e}}\right)=1.70 \%$

Table 3. The physical values of Apelblat parameters ( $A, B$ and $C$ ) along with $R^{2}$ and $\%$ RMSD for brigatinib in various pure solvents (S).

\begin{tabular}{|c|c|c|c|c|c|}
\hline$S$ & $A$ & $B$ & $C$ & $R^{2}$ & $R M S D(\%)$ \\
\hline Water & 236.33 & -14764.00 & -35.01 & 0.9998 & 0.9992 \\
\hline Ethanol & 212.16 & -13630.30 & -30.15 & 0.9986 & 3.96 \\
\hline PEG-400 & 955.72 & -50246.50 & -138.93 & 0.9998 & 4.74 \\
\hline IPM & -203.11 & 6964.35 & 31.05 & 0.9999 & 4.47 \\
\hline EA & 772.13 & -40322.80 & -112.78 & 0.9989 & 1.91 \\
\hline DCM & -283.64 & 10202.79 & 43.15 & & \\
\hline
\end{tabular}

Table 4. The physical values of van't Hoff model parameters (a and b) along with $R^{2}$ and \% RMSD for brigatinib various pure solvents $(\mathrm{S})$.

\begin{tabular}{|c|c|c|c|c|}
\hline$S$ & $a$ & $b$ & $R^{2}$ & $R M S D(\%)$ \\
\hline Water & 0.30 & -3870.10 & 0.9992 & 1.25 \\
\hline Ethanol & 8.88 & -4246.50 & 0.9988 & 1.32 \\
\hline PEG-400 & 19.27 & -7034.20 & 0.9949 & 4.46 \\
\hline IPM & 6.21 & -2689.70 & 0.9983 & 1.09 \\
\hline EA & 11.91 & -5243.00 & 0.9955 & 3.05 \\
\hline DCM & 7.19 & -3211.30 & 0.9970 & 1.76 \\
\hline
\end{tabular}

Table 5. The physical values of apparent thermodynamic parameters $\left(\ddot{\mathrm{A}}_{\text {sol }} H^{0}, \ddot{\mathrm{A}}_{\text {sol }} G^{0}\right.$ and $\left.\ddot{\mathrm{A}}_{\text {sol }} S^{0}\right)$ along with $R^{2}$ values for brigatinib various pure solvents $(S)^{\mathrm{b}}$.

\begin{tabular}{|c|c|c|c|c|}
\hline$S$ & $\Delta_{\text {sol }} H^{0} / \mathrm{kJ} \mathrm{mol}^{-1}$ & $\Delta_{\text {sol }} G^{0} / \mathrm{kJ} \mathrm{mol}^{-1}$ & $\Delta_{\text {sol }} S^{0} / \mathrm{J} \mathrm{mol}^{-1} \mathrm{~K}^{-1}$ & $R^{2}$ \\
\hline Water & 32.14 & 31.38 & 2.44 & 0.9992 \\
\hline Ethanol & 35.26 & 12.49 & 73.71 & 0.9988 \\
\hline PEG-400 & 58.42 & 8.96 & 160.07 & 0.9950 \\
\hline IPM & 22.33 & 6.40 & 51.55 & 0.9957 \\
\hline EA & 43.54 & 12.99 & 98.86 & 0.9969 \\
\hline DCM & 26.66 & 8.21 & 59.73 & \\
\hline
\end{tabular}

${ }^{\mathrm{b}}$ The relative uncertainties are $u\left(\Delta_{\mathrm{sol}} H^{0}\right)=0.35 \mathrm{~kJ} \mathrm{~mol}^{-1}, u\left(\Delta_{\mathrm{sol}} G^{0}\right)=0.68 \mathrm{~kJ} \mathrm{~mol}^{-1}$ and $u\left(\Delta_{\mathrm{sol}} S^{0}\right)=0.70 \mathrm{~J} \mathrm{~mol}^{-1} \mathrm{~K}^{-1}$ 


$$
\ln x^{\mathrm{Apl}}=A+B / T+\mathrm{Cln}(T)
$$

The experimental and theoretical (Apelblat) solubilities of BGB were calculated with the help of Apelblat coefficients.

Where, $\mathrm{A}, \mathrm{B} \& \mathrm{C}=$ these are adjustable equation parameters, calculate by multivariate regression analysis of experimental data. The Apelblat parameters A, $\mathrm{B} \& \mathrm{C}$ were used to calculate the calculated/ Apelblat solubilities of BGB. The correlation between experimental $\left(x_{\mathrm{e}}\right)$ and Alpblat solubilities $\left(x_{\mathrm{Ac}}\right)$ in various solvents like water, ethanol, IPM, PEG-400, EA, and DCM from (298.2 to 323.2) $\mathrm{K}$ at atmospheric pressure of $0.1 \mathrm{MPa}$ are given in Figure 4.

The deviations values between $x_{\mathrm{e}}$ and $x_{\mathrm{Ac}}$ for BGB were calculated with the help of root mean square deviations (RMSD) equation-3 (19).

$$
R M S D=\left[\frac{1}{\mathrm{~N}} \sum_{\mathrm{i}=1}^{\mathrm{N}}\left(\frac{x^{\mathrm{Apl}}-x_{\mathrm{e}}}{x_{\mathrm{e}}}\right)^{2}\right]^{1 / 2}
$$

where, $\mathrm{N}=$ number of data points in experiment.

The values of Apelblat parameters A, B and C along with $R^{2}$ and $R M S D$ in water, ethanol, IPM, PEG400, EA and DCM are documented in Table 3.

The higher \% RMSD values, 4.67 and 4.47 were obtained in IPM and EA solvents respectively in comparison to other solvents used in this study. The $R^{2}$ values for BGB in all six different pure solvents varied around 0.9986 to 0.9999 . These data clearly indicated good correlation between $x_{\mathrm{e}}$ values and $x_{\mathrm{AC}}$ for BGB.

\section{Van't Hoff correlation of experimental solubilities of brigatinib}

The van't Hoff analysis utilized to determine the dissolution enthalpy in all pure solvents (20). The van't Hoff model solubility ( $x^{\text {van't })}$ of BGB was calculated using equation-4:

$$
\ln x^{\mathrm{van} / \mathrm{t}}=a+b / T
$$

Here, $\mathrm{a} \& \mathrm{~b}$ are the factors of van't Hoff equation. The $\ln x_{\mathrm{e}}$ values of BGB was plotted against $1 / T$ to determine the physical values of the parameter. The $x_{\mathrm{e}}$ values corresponded with $x^{\mathrm{van} t}$ values of BGB again as far as $R M S D$ and $R^{2}$ values. The correlations between $x_{\mathrm{e}}$ and $x^{\text {van't }}$ values of brigatinib in all pure solvent against $1 / T$ were presented in Figure 5. The data obtained for van't Hoff correlation are listed in Table 4.

The percentage of $R M S D$ values for BGB in six selected pure solvents were determined in the range of 1.09 to $4.46 \%$. The maximum $R M S D$ values recorded in solvent PEG-400 (4.46\%) followed by EA $(3.05 \%)$, DCM $(1.76 \%)$, Ethanol $(1.32 \%)$, Water $(1.25 \%)$ and IPM $(1.09 \%)$. However, the $R^{2}$ values were calculated in the range of 0.9955 to

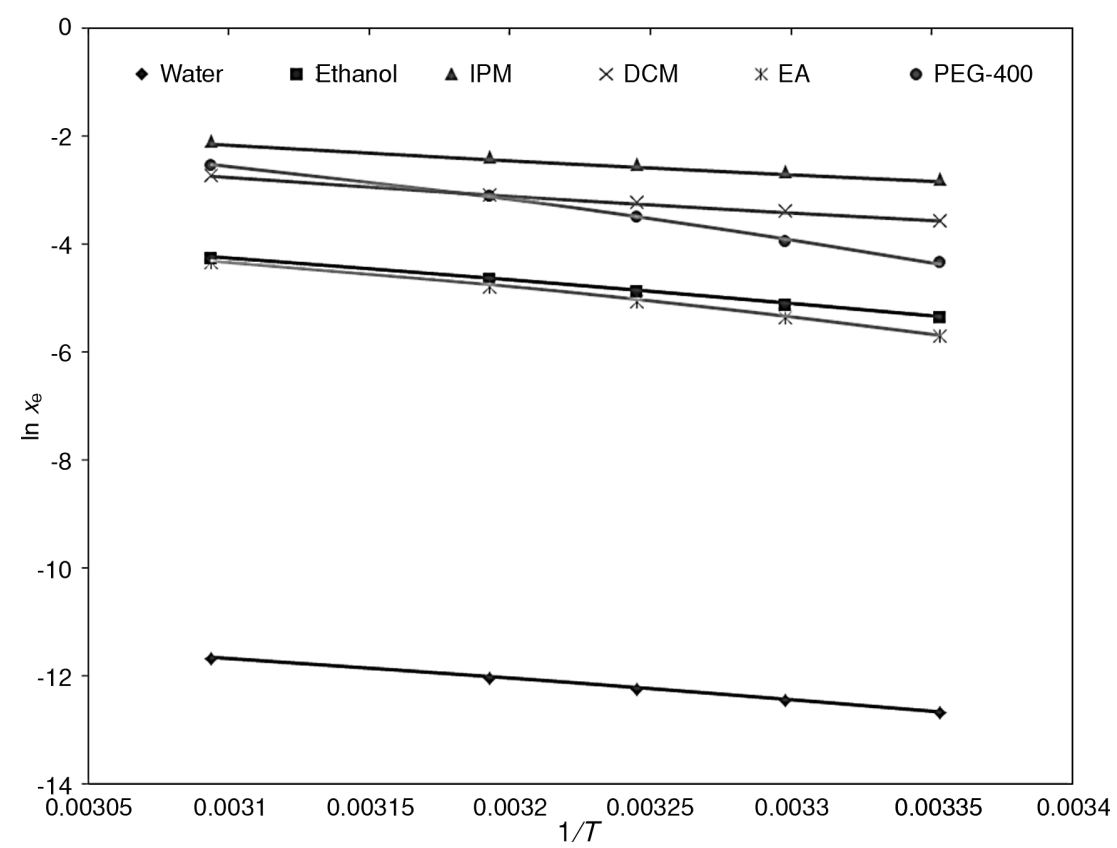

Figure 4. Correlation of lnxe values of brigatinib with "Apelblat model" in various pure solvents; water, ethanol, IPM (Isopropyl myristate), DCM (Dichloromethane), EA (Ethyl acetate), PEG-400 (polyethylene glycol 400) against 1/T; symbols represent the experimental solubilities of BGB and solid lines represent the solubilities of BGB calculated by "Apelblat model" 


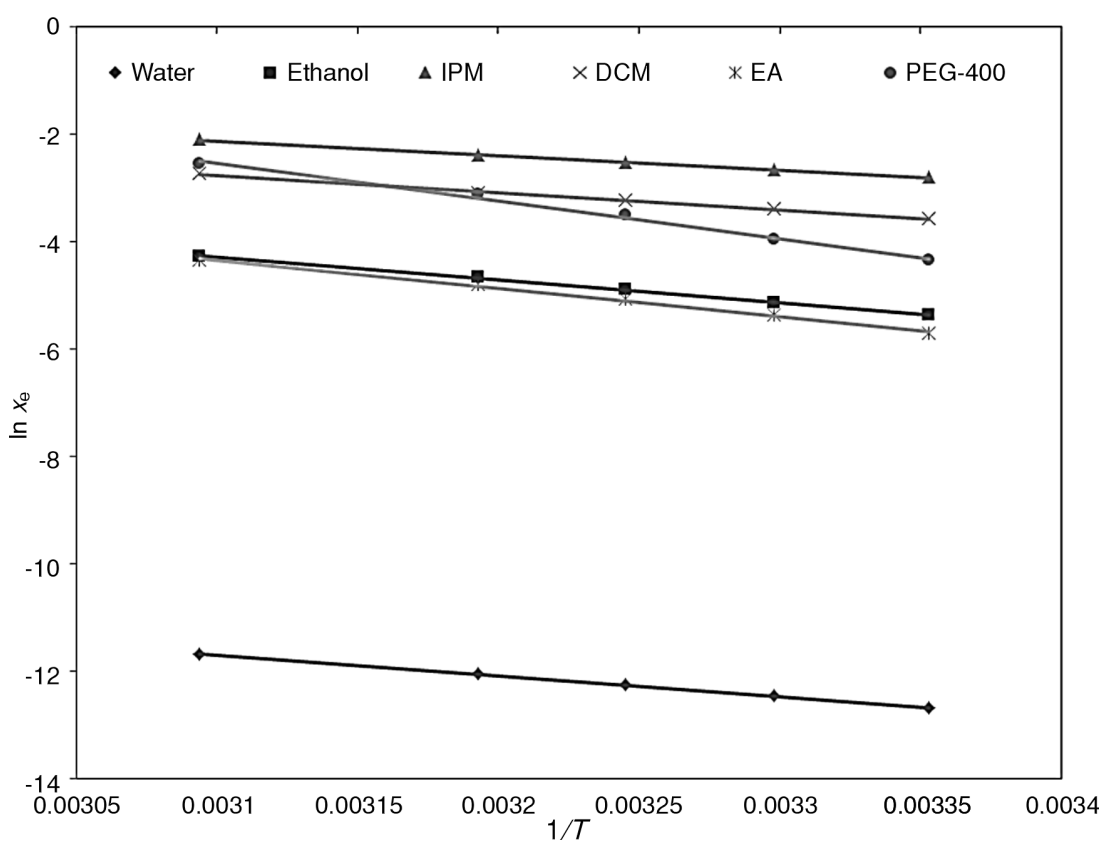

Figure 5. Correlation of $\ln x_{\mathrm{e}}$ values of brigatinib with "van't Hoff model” in various pure solvents; water, ethanol, IPM (Isopropyl myristate), DCM (Dichloromethane), EA (Ethyl acetate), PEG-400 (polyethylene glycol 400) against 1/T; symbols represent the experimental solubilities of BGB and solid lines represent the solubilities of BGB calculated by "van't Hoff model"

0.9992. This data again indicated a good correlation of experimental solubilities of BGB $\left(x_{\mathrm{e}}\right)$.

\section{Apparent thermodynamic parameters of briga- tinib}

Apparent thermodynamic dissolution of BGB in six different pure solvents was assessed utilizing apparent thermodynamic analysis. The thermodynamic parameters for BGB dissolution such as apparent standard dissolution enthalpy $\left(\Delta_{\text {sol }} H^{0}\right)$, apparent standard Gibbs free energy $\left(\Delta_{\text {sol }} G^{0}\right)$ and apparent standard dissolution entropy $\left(\Delta_{\text {sol }} S^{0}\right)$ were measured by using van't Hoff analysis. The BGB dissolution was calculated at mean harmonic temperature $\left(T_{\mathrm{hm}}\right)$ with the of van't Hoff analysis using equation-5 $(21,22)$.

$$
\left(\frac{\delta \ln x_{\mathrm{e}}}{\delta\left(1 / \mathrm{T}^{-1} / \mathrm{T}_{\mathrm{hm}}\right)}\right)_{\mathrm{p}}=\frac{\Delta_{\mathrm{sol}} H^{0}}{}
$$

The values of dissolution enthalpy $\left(\Delta_{\text {sol }} H^{0}\right)$ and dissolution entropy $\left(\Delta_{\text {sol }} S^{0}\right)$ were documented in the Table. 5. The dissolution Gibb's free energy $\left(\Delta_{\text {sol }} G^{0}\right)$ and dissolution entropy $\left(\Delta_{\text {sol }} S^{0}\right)$ for BGB were calculated by using Equations 6 and 7 respectively (23).

$$
\begin{gathered}
\Delta_{\mathrm{sol}} G^{0}=-R T_{\mathrm{hm}} \times \text { intercept } \\
\Delta_{\mathrm{sol}} S^{0}=\frac{\Delta_{\mathrm{sol}} H^{0}-\Delta_{\mathrm{sol}} G^{0}}{T_{\mathrm{hm}}}
\end{gathered}
$$

Maximum values of dissolution enthalpies $\left(\Delta_{\text {sol }} H^{0}\right)$ and dissolution entropy $\left(\Delta_{\text {sol }} S^{0}\right)$ were estimated in PEG-400 and EA among different solvents used in the study at temperature run, 298.2 to 323.2 K for BGB dissolution (Table 5). A positive value of dissolution enthalpies $\left(\Delta_{\text {sol }} H^{0}\right)$ confirmed its endothermic reaction with a strong bonding/interaction between BGB and solvent molecules as compared to solvent/solvent and BGB/ brigatinib interaction. The value of dissolution enthalpy $\left(\Delta_{\text {sol }} H^{0}\right)$ observed significantly lower in IPM as compared to other solvents indicated that low energy required for solubilization of BGB in IPM solvent.

\section{CONCLUSION}

In conclusion, the thermodynamic solubilities of brigatinib in pharmaceutically useful solvents (water, Ethanol, EA, PEG-400, IPM, and DCM) were determined at temperature $298.2 \mathrm{~K}$ to $323.2 \mathrm{~K}$. The maximum solubility of brigatinib was measured in IPM solvent at all temperatures in comparison to other solvents used in the study.

The experimental solubilities data of brigatinib were successfully correlated with Apelblat model in solvents. The data generated from van't Hoff analy- 
sis confirmed endothermic and entropy driven in all solvents. This solubility's analysis of brigatinib could be useful for analytical methods and formulation development.

\section{Acknowledgment}

The Deanship of Scientific Research, Prince sattam Bin Abdulaziz University, Alkharj, Saudi Arabia funded this project (Project no.2017/03/ 7329).

\section{Conflict of interest}

No conflict of interest is associated with this study.

\section{REFERENCES}

1. Huang W.S., Liu S., Zou D., Thomas M., Wang Y. et al.: J. Med. Chem. 59, 4948 (2016).

2. Sabari J.K., Santini F.C., Schram A.M., Bergagnini I., Chen R. et al.: Onco. Targets. Ther. 10, 1983 (2017).

3. Cruz C.S.D., Tanoue L.T., Matthay R.A.: Clin. Chest. Med. 32, 1 (2013).

4. Gettinger S.N., Bazhenova L.A., Langer C.J., Salgia R., Gold K.A. et al.: Lancet. Oncol. 17,1683 (2016).

5. Zhang S., Anjum R., Squillace R., Nadworny S., Zhou T. et al.: Clin. Cancer. Res. 22, 5527 (2016).

6. Markham A.: Drugs. 77, 1131 (2017).

7. Compound Summary for CID 68165256. Brigatinib. PubChem, Open chemistry database. US National Library of medicine.
8. Shakeel F., Anwer M.K.: Drug. Dev. Ind. Pharm. 20, 1 (2015).

9. Anwer M.K., Al-Shdefat R., Jamil S., Alam P., Abdel-Kader M.S., Shakeel F.: J. Chem. Eng. Data. 59, 2065 (2014).

10. Kalam M.A., Khan A., Alshamsan A., Haque A., Shakeel F.: J. Mol. Liquids. 249, 53 (2018).

11. Anwer M.K., Shakeel F.: Chinese. J. Chem. Eng. 23, 812 (2015).

12. Higuchi T., Connors K.A.: Adv. Anal. Chem. Instr. 4, 117 (1965).

13. Anwer M.K.: Latin. Am. J. Pharm. 34, 1571 (2015).

14. Alshehri S., Haq N., Shakeel F.: J. Mol. Liquids. 250, 63 (2018).

15. Shakeel F., Haq N., Alshehri S., Ibrahim M.A., Elzayat E.M. et al.: J. Mol. Liquids. 255, 43 (2018).

16. Uchibori K., Inase N., Araki M., Kamada M., Sato S. et al.: Nat. Comm. 8, 14768 (2017).

17. Apelblat A., Manzurola E.: J. Chem. Thermodyn. 31, 85 (1999).

18. Manzurola E., Apelblat A.: J. Chem. Thermodyn. 34, 1127 (2002).

19. Shakeel F., Haq N., Raish M., Anwer M.K., AlShdefat R.: J. Mol. Liquids. 222, 167 (2016).

20. Shakeel F., Haq N., Alanazi F.K., Alsarra I.A.: Int. J. Pharm. 523, 410 (2017).

21. Holguin A.R., Rodriguez G.A., Cristancho D.M. et al.: Fluid Ph. Equilibria 314, 134 (2012).

22. Ruidiaz M.A., Delgado D.R., Martýnnez F., Marcus Y.: Fluid Ph. Equilibria 299, 259 (2010).

23. Krug R.R., Hunter W.G., Grieger R.A.: J. Phys. Chem. 80, 2341 (1976).

Received: 16.03. 2018 